Check for updates

Cite this: Chem. Sci., 2019, 10, 8187

๑ All publication charges for this article have been paid for by the Royal Society of Chemistry

Received 9th July 2019

Accepted 19th July 2019

DOI: $10.1039 / \mathrm{c} 9 \mathrm{sc} 03378 \mathrm{e}$

rsc.li/chemical-science

\title{
Metal-free perovskites for non linear optical materials $\uparrow$
}

\author{
Thomas W. Kasel, (D) $\ddagger^{a}$ Zeyu Deng, (D) $\ddagger^{b}$ Austin M. Mroz, (D) $\ddagger^{a}$ \\ Christopher H. Hendon, (D) *a Keith T. Butler (D) ${ }^{* c}$ and Pieremanuele Canepa (DD ${ }^{\star b}$
}

\begin{abstract}
We identify the existence of non linear optical (NLO) activity in a number of novel $A B X_{3}$-type metal-free perovskites, where $\mathrm{A}$ is a highly tuneable organic cation, $\mathrm{B}$ is $\mathrm{NH}_{4}$ cation and $\mathrm{X}$ is a halide anion. Through systematic first-principles calculations, we identify important trends to chart the secondharmonic generation of this class of materials. We study three perovskites MDABCO- $\mathrm{NH}_{4} \mathrm{I}_{3}, \mathrm{CNDABCO}-$ $\mathrm{NH}_{4} \mathrm{I}_{3}$ and ODABCO- $\mathrm{NH}_{4} \mathrm{I}_{3}$ for use as deep-UV second-harmonic generation materials. We identify the role of the dipole moment imparted by the organic group on the A cation as an important parameter to tune the NLO properties of these materials. We apply this knowledge functionalising the organic group DABCO with the highly polar cyanide $\mathrm{CN}^{-}$group, and we demonstrate a significant improvement of the NLO response in this family of materials. These findings can accelerate the application of metalfree perovskites as inexpensive, non-toxic, earth-abundant materials for the next generation of optical communication applications.
\end{abstract}

\section{Introduction}

Light has been utilized as a communication device for many centuries. Recently, non-linear optics (NLO) and second harmonic generation (SHG) have been at the heart of several technological revolutions. With the advent of the internet, conveying information and data by means of fiber-optics and lasers have transformed telecommunications. The development of fiber-optic devices with increased performance has fuelled a surge of interest in the development of materials with everincreasing data-transfer capabilities. ${ }^{1-10}$ Materials, such as $\mathrm{LiNbO}_{3}$ and $\mathrm{LiTaO}_{3}$ with NLO and SHG are at the core of highspeed electro-optic modulator devices, significantly boosting the transmission capacities of the telecommunication infrastructure $\left.\left(\sim 10 \mathrm{Gbit} \mathrm{s}^{-1}\right)\right)^{1,11}$ In parallel NLO materials for deepUV lasers are being used in semiconductor manufacturing, photolithography, laser systems, and advanced instrument development.

The demand for apparatus with increased performance requires the development of novel inexpensive NLO materials

\footnotetext{
${ }^{a}$ Department of Chemistry and Biochemistry, University of Oregon, Eugene, OR 97403, USA.E-mail: chendon@uoregon.edu

${ }^{b}$ Department of Materials Science and Engineering, The National University of Singapore, 117575, Singapore.E-mail: pcanepa@nus.edu.sg

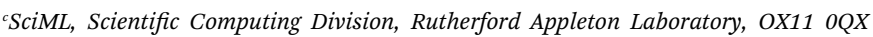
Harwell, UK. E-mail: keith.butler@stfc.ac.uk

$\dagger$ Electronic supplementary information (ESI) available: Structural properties, band gaps, dielectric constants, refractive indexes values of $\chi^{(1)}$, values of $\chi^{(2)}$ and $d_{\text {norm }}$, respectively. See DOI: $10.1039 / \mathrm{c} 9 \mathrm{sc} 03378 \mathrm{e}$

\$ These authors contributed equally.
}

and every year the electronic and telecommunication industries demands the production of $\sim 40000$ tons of $\mathrm{LiNbO}_{3}$. The soaring costs of lithium and niobium, ${ }^{12,13}$ and thus $\mathrm{LiNbO}_{3}$ requires the development of the new generation of NLO materials relying on more earth-abundant elements. ${ }^{14-16}$ This is further aggravated by the fact that $\mathrm{LiNbO}_{3}$ melts incongruently and the manufacturing of congruently lithium niobate single crystals requires cooling of Li-poor nonstoichiometric melts of $\mathrm{LiNbO}_{3},{ }^{17}$ adding additional production costs.

Meanwhile, for deep-UV applications Tran et al. ${ }^{9}$ have shown that only a handful of materials, such as $\mathrm{KBe}_{2} \mathrm{BO}_{3} \mathrm{~F}_{2}, \mathrm{RbBe}_{2}$ $\mathrm{BO}_{3} \mathrm{~F}_{2}$ and $\mathrm{CsBe}_{2} \mathrm{BO}_{3} \mathrm{~F}_{2}$, sharing similar structural features currently fulfil the desired requirements. However, these materials contain toxic Be, whose usage is prohibited in many countries. Therefore, materials with better NLO characteristics are required to supplant deep-UV lasers. ${ }^{10}$ As identified by Halasyamani and Rondinelli, ${ }^{10}$ NLO materials for application in deep-UV lasers must fulfil a minimal number of requirements: (i) the atoms in the material should present a noncentrosymmetric arrangement, (ii) the material absorbs light in the deep-UV spectrum (i.e., absorption wavelengths $\geq 175 \mathrm{~nm}$ ), and (iii) the material should respect the phase-matching criteria discussed in detail within the manuscript.

One promising route towards sustainable NLO materials lies in organic materials, which have shown promising SHG properties. ${ }^{3,18-28}$ However, to date organic NLO suffer from thermal instability and difficult fabrication. In contrast to typical organic-based NLO, metal-free perovskites have been shown to be structurally stable beyond $200{ }^{\circ} \mathrm{C} .{ }^{29}$ 
In this study we present an in-depth analysis of the NLO properties of a new class of materials with ferroelectric response termed metal-free perovskites developed by Ye and coworkers. ${ }^{29}$ We use first-principles calculations, based on density functional theory (DFT) to chart the optical and NLO properties of a these novel metal-free perovskites. In contrast to typical inorganic perovskite $\mathrm{A}^{2+} \mathrm{B}^{4+} \mathrm{O}_{3}{ }^{2-}$ where $\mathrm{A}$ and $\mathrm{B}$ are metal cations (e.g., $\mathrm{CaTiO}_{3}$ ), in metal-free perovskites the $\mathrm{A}$ and $\mathrm{B}$ cations are replaced by organic units. The rich choice of organic units introduces the possibility of tailoring the functional properties of such metal-free perovskites, while being easy-tosynthesise, affordable and non-toxic. Note that NLO materials with inorganic perovskite structures exist (e.g., $\mathrm{K}_{3} \mathrm{~B}_{6} \mathrm{O}_{10} \mathrm{Cl}$ ) which are more closely related to the metal-free perovskites than organic-based NLO materials. ${ }^{30}$

We investigate such metal-free perovskites as NLO materials for SHG applications, and verify whether these perovskites are suitable as deep-UV NLO materials. Our findings reveal that metal-free perovskites, based on the organic moieties $N$-methyl$\mathrm{N}$-diazabicyclo[2.2.2] octonium $\left(\mathrm{MDABCO}^{2+}\right)$ and $\mathrm{N}$-hydroxy- $\mathrm{N}$ diazabicyclo[2.2.2] octonium $\left(\mathrm{ODABCO}^{2+}\right)$, posses SHG response, with magnitudes similar to some inorganic contenders, such as $\mathrm{KBe}_{2} \mathrm{BO}_{3} \mathrm{~F}_{2}, \mathrm{RbBe}_{2} \mathrm{BO}_{3} \mathrm{~F}_{2}$ and $\mathrm{CsBe}_{2} \mathrm{BO}_{3} \mathrm{~F}_{2}$. We demonstrate that organic groups presenting intrinsic dipole moments can contribute positively to the ferroelectric response of the material, and provide an increased NLO response.

On the basis of our predictions, we provide guidelines to improve the SHG response of the metal-free perovskites, by tailoring the structural features of the organic cations. Following this principle, we extend the computational search to new structures. For example, we show the case where the hydroxy-group in $\mathrm{ODABCO}^{2+}$ (A-cation) is effectively replaced by a cyanide $\mathrm{CN}^{-}$group with increased polarity, which provides remarkable NLO response. While preliminary observations ${ }^{29}$ showed experimentally SHG response in MDABCO- $\mathrm{NH}_{4} \mathrm{I}_{3}$, we also identify ODABCO- $\mathrm{NH}_{4} \mathrm{I}_{3}$ and CNDABCO-NH $\mathrm{I}_{3}$ as superior SHG materials, and their properties should be carefully verified experimentally.

\section{Results}

\subsection{Structure of ferroelectric metal-free perovskites}

The first point when considering the suitability of a material for NLO applications is the crystal structure. All materials reported herein and shown in Fig. 1 feature the typical perovskite $\mathrm{ABX}_{3}$ structure (where $\mathrm{A}$ and $\mathrm{B}$ are cations and $\mathrm{X}$ are anions), with $\mathrm{BX}_{3}$ corner-sharing octahedra and charge-balancing A cations in the cavities of the framework. The structures investigated have $\mathrm{NH}_{4}{ }^{+}$as B sites and halide $\mathrm{X}^{-}$sites, as seen in Fig. 1. A series of different A site divalent molecular cations are considered (i) $\mathrm{N}$ methyl- $N$-diazabicyclo[2.2.2] octonium $\left(\mathrm{MDABCO}^{2+}\right)$, (ii) $\mathrm{M}$ hydroxy- $N$-diazabicyclo[2.2.2] octonium $\left(\mathrm{ODABCO}^{2+}\right)$, (iii) $R-3$ ammonioquinuclidinium $\left(R-3 \mathrm{AQ}^{2+}\right)$, and (iv) $S$-3-ammoniopyrrolidinium $\left(S-3 \mathrm{AP}^{2+}\right)$. Starting from the ODABCO- $\mathrm{NH}_{4} \mathrm{X}$ structures, we also replaced the hydroxy group with a more polar cyanide $\mathrm{CN}^{-}$group forming a new metal-free perovskite termed CNDABCO- $\mathrm{NH}_{4} \mathrm{X}_{3}$. In studying the halide chemical

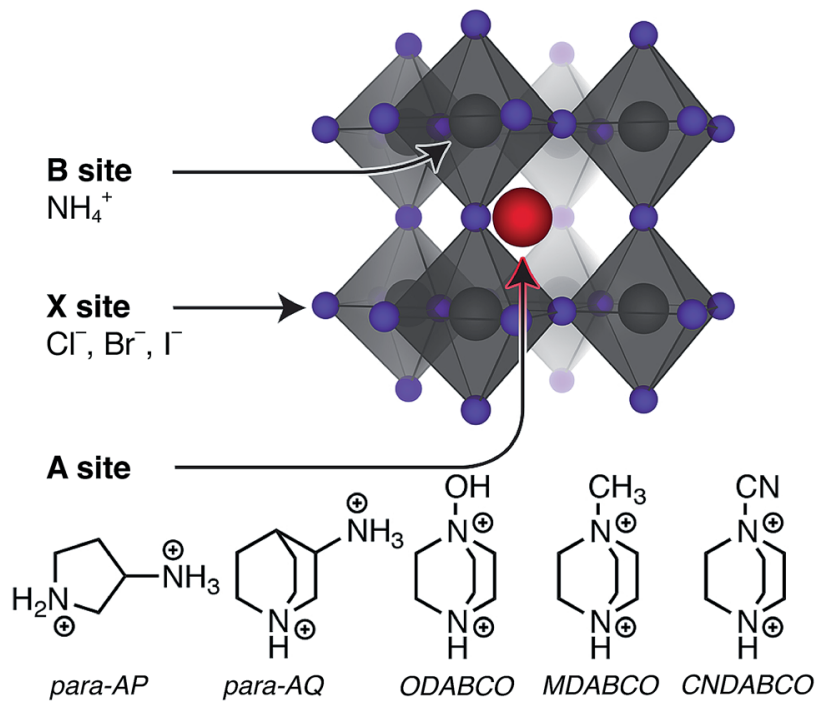

Fig. 1 Polyhedra representation of a metal-free $\mathrm{ABX}_{3}$-type perovskite, where $A$ can be one of the four organic cations (also shown by the red ball), $\mathrm{B}$ is $\mathrm{NH}_{4}^{+}$(grey ball) and $\mathrm{X}$ the halide ion, i.e. $\mathrm{Cl}^{-}, \mathrm{Br}^{-}$and $\mathrm{I}^{-}$ (purple balls). The nature of the $\mathrm{A}$ cation is also shown.

space of these metal-free perovskites, we proposed three new structures, including MDABCO- $\mathrm{NH}_{4} \mathrm{Cl}_{3}$, ODABCO- $\mathrm{NH}_{4} \mathrm{I}_{3}$ and $S$ $3 \mathrm{AP}-\mathrm{NH}_{4} \mathrm{I}_{3}$ that were not identified by Ye et al. ${ }^{29}$ In the case of ODABCO- $\mathrm{NH}_{4} \mathrm{I}_{3}$ and CNDABCO- $\mathrm{NH}_{4} \mathrm{X}_{3}$ we assumed a $R 3$ space group. However, we also computed the iodine-based polymorph with $\mathrm{Pca}_{1}$ space group (as in ODABCO- $\mathrm{NH}_{4} \mathrm{Cl}_{3}$ ), which converted to the $R 3$ polymorph.

To be NLO active a material must be non-centrosymmetric. As shown in Tables S1 and S2 of the ESI, $\dagger$ the materials considered here fall into three space groups, $R 3, P c a 2_{1}$ and $P 2_{1}$, all of which are non-centrosymmetric. For those metal-free perovskites that have been synthesized and characterized previously the noncentrosymmetric space groups persisting up to $448 \mathrm{~K}^{29}$

In addition, metal-free perovskites, and inorganic materials, such as $\mathrm{LiNbO}_{3}$ posses an intrinsic polarization, which is typical of ferroelectric materials. $\mathrm{LiNbO}_{3}$ charts among the most popular of NLO materials with a polarization of $\sim 70-75 \mu \mathrm{C}$ $\mathrm{cm}^{-2} \cdot{ }^{31}$ The presence of dipolar molecules and the off-centring of the B-site cation in the metal-free perovskites indicates the existence of an intrinsic polarization, which for MDABCO$\mathrm{NH}_{4} \mathrm{I}_{3}$ has been measured to be $\sim 19 \mu \mathrm{C} \mathrm{cm}^{-2}{ }^{29}$

\subsection{Birefringence activity of metal-free perovskites}

Having established the crystallographic criteria for NLO materials, we now consider the optical properties that must be satisfied for SHG. The birefringence is the maximum difference refractive indices $(n)$ which depends on the propagation directions of light in the crystal at a fixed frequency ( $\omega)$ (as in eqn (1)).

$$
\Delta n=n_{\max }(\omega)-n_{\min }(\omega)
$$

SHG occurs efficiently whenever the refractive index $n$ of the $2^{\text {nd }}$ harmonic is equal (or close) to that of the generating wave at 
half-frequency, i.e., $n(2 \omega)=n(\omega)$; this condition is termed phase-matching. Phase-matching requires a suitable range of frequencies with refractive indexes, $n_{\max }(\omega)-n_{\min }(2 \omega)>0$, with $n_{\min }$ and $n_{\max }$ the lowest and the largest refractive index in the spread. $^{32}$

If $\Delta n$ of a material is too small the phase-matching condition for SHG will not occur. If $\Delta n$ is too large the material will exhibit spatial beam walk-off, where the intensity distribution of the wave drifts away from the direction of propagation resulting in reduced SHG intensity. In general a moderate birefringence $(\Delta n$ $\approx 0.07$ ) is desired.

In uniaxial systems, such as $\mathrm{LiNbO}_{3}$ and the MDABCO$\mathrm{NH}_{4} \mathrm{X}_{3}$ systems the direction of ordinary and extraordinary rays occurs along the optical axis, which lays along the highest symmetry axis.

In contrast, biaxial systems have multiple optic axes, whose directions of propagation depend on the diffraction index and measured by the $2 \mathrm{~V}$ acute angle (see below).$^{32}$ Therefore, the $2 \mathrm{~V}$ angle provides information about the nature of the birefringence in biaxial crystals. In general, orthorhombic, monoclinic and triclinic systems are biaxial crystals.

Fig. 2 plots $\Delta n$ (obtained from the dielectric constants in the static regime) and the $2 V$ acute angle. From Fig. 2, we observe that all the systems considered here have $\Delta n$ ranging between values of -0.03 and +0.05 , with CNDABCO, ODABCO, $S$-3AP and $R$-3AQ-based perovskites charting among the highest in magnitude. The $R 3$ materials, which are uniaxial NLO systems, all exhibit positive birefringence. In contrast, the $P c a 2_{1}$ and $P 2_{1}$ systems, which are biaxial NLO materials, display both positive and negative birefringence. A closer look at Fig. 2 shows that with the exception of MDABCO-based perovskites and $S$-3AP$\mathrm{NH}_{4} \mathrm{I}_{3}$ (whose $2 \mathrm{~V} \sim 0$ ), the remaining materials all show a rather complex biaxial response.

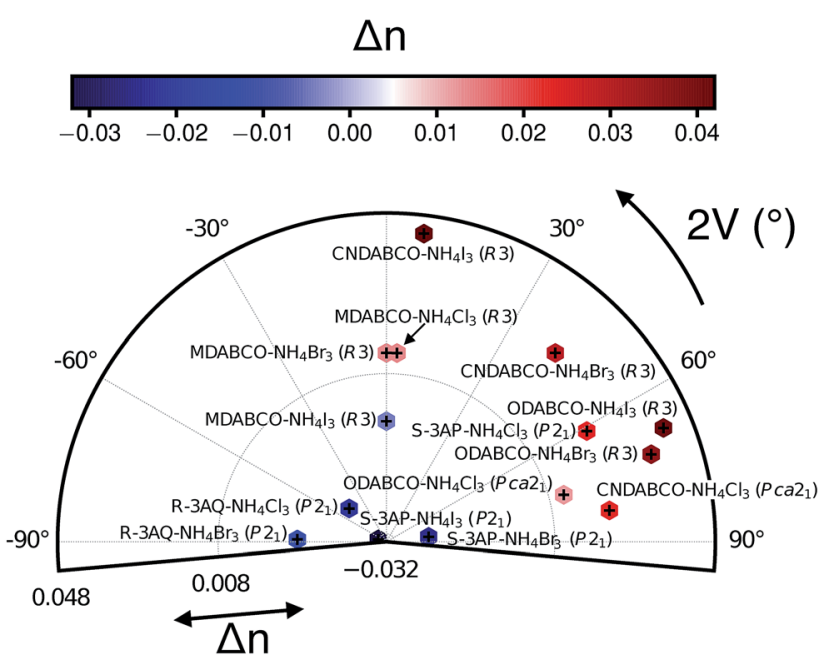

Fig. 2 Computed birefringence $\Delta n$ and $2 V$ angle of metal-free perovskites at their experimental volume and lattice constants. $\Delta n$ is plotted on the radial axis and using the colour-bar, with red indicating positive $\Delta n$. Values of $n$ are given in Table S3 of the ESI. $\uparrow$ The $2 \mathrm{~V}$ angles provide information about the nature of the birefringence in biaxial crystals.

\subsection{NLO response in metal-free perovskites}

We now discuss the NLO response of the metal-free perovskites. Among the prerequisites for SHG the materials under investigation should display a non-negligible value of the second order dielectric tensor, $\chi^{(2)}$.

$\chi_{i j k}^{(2)}=2 d_{i j k}$ is a third-rank tensor as defined in eqn (6), and therefore can be difficult to analyse intuitively. The $i, j$ and $k$ components of the $d$ tensor identify the directions of the applied electric fields (i.e., $j$ and $k$ ) of the incident radiation and the polarization of the generated second harmonic (i.e., i), respectively, (see eqn (6)). In SHG experiments, the directions of the electric fields of incident radiations have frequencies $\omega_{1}$ and $\omega_{2}$ (with $\omega_{1}=\omega_{2}$ in SHG) and the second harmonic wave with frequency $\omega_{3}=\omega_{1}+\omega_{2}$. A complete discussion of the $\chi^{(2)}$ and $d$ tensors and their dependence can be found in ref. 33 .

A useful proxy for presenting the $i j k$ component of the static $\chi^{(2)}$ tensor is the norm of the $d_{i j k}$ components of Table 1 and eqn (2):

$$
\left\|d_{\text {norm }}\right\|=\sqrt{\sum_{i j k} d_{i j k}^{2}}
$$

$d_{\text {norm }}$ has been utilized previously ${ }^{\mathbf{1 6 , 3 4}}$ and is more effective of a simple geometric mean of the $d_{i j k}$ components, which can assume values approaching numerical zeros given the oscillations in sign of the $d_{i j k}$ values (see Table 1). We note that the values $d_{\text {norm }}$ are by definition larger in magnitude of any component $d_{i j k}$, but here $d_{\text {norm }}$ serves us simply to compare each materials investigated on the same footing.

Fig. 3 presents the static dielectric constant $\varepsilon$ (y-axis) as a function of the band gap ( $x$-axis) for the materials studied, the data points are coloured according to the magnitude of $d_{\text {norm }}$, which are obtained at the experimental volumes at room temperature. The values of band gap, $\varepsilon, \chi^{(1)}, \chi_{i j k}^{(2)}$ and $d_{\text {norm }}$ of these materials are found in Tables S4 and S5. $\dagger$

In general, volumes obtained after relaxation in hybrid systems containing a number of van der Waals interactions, such as these metal-free perovskites, tend to be highly distorted. Therefore, the main text concentrates on results obtained on structures where all the atomic coordinates are relaxed at the experimental volumes and lattice constants, whereas results on fully relaxed structures are available in the ESI. $\dagger$ For clarity and ease of comparison, the dielectric constant and the $d_{\text {norm }}$ are scaled by that of $\mathrm{LiNbO}_{3}$, calculated at the same level of theory (Tables $\mathrm{S} 4$ and $\mathrm{S} 5 \dagger$ ).

The $y$-axis of Fig. 3 presents the average dielectric constant (in the static limit) of the metal-free perovskites rescaled to that of $\mathrm{LiNbO}_{3} \sim 4.39$, which compare well with experimental data $(\sim 4.87) .{ }^{31}$ The computed $d_{z z z}$ values of $16.45 \mathrm{pm} \mathrm{V}^{-1}$ (at the experimental volume of $\mathrm{LiNbO}_{3}$ ) slightly underestimated the experimental value of $\left(\sim 22.0 \mathrm{pm} \mathrm{V}^{-1}\right.$ at $\left.\lambda \sim 407.2 \mathrm{~nm}\right)$ by Magel et $a l .{ }^{35}$ DFT has been known to systematically underestimate values of $d$ in NLO materials. ${ }^{36}$ The complete dielectric and $d$ tensors of each metal-free perovskites are reported in the ESI. $\dagger$

The computed band gaps of Fig. 3 are characteristic of highgap insulators ranging between $\sim 5.5$ and $8 \mathrm{eV}$. The metal-free perovskites absorb light between 155 and $220 \mathrm{~nm}$, i.e. the 
Table 1 Computed static $d_{i j k}$ components of the $\chi^{(2)}$ tensor and their norm $d_{\text {norm }}$ (in $p m V^{-1}$ ) of the metal-free perovskites at the experimental volumes. Spg. is the space group

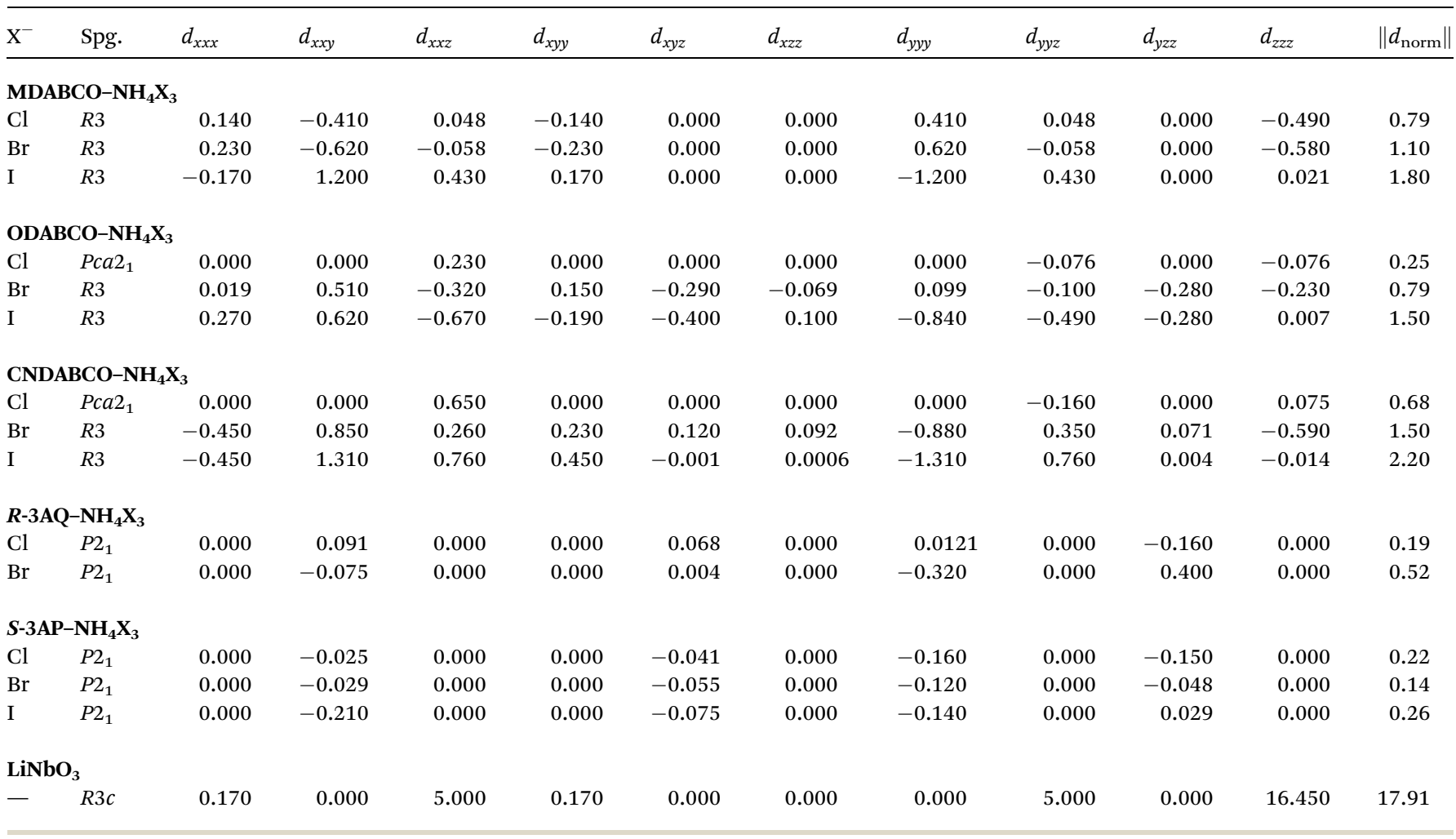

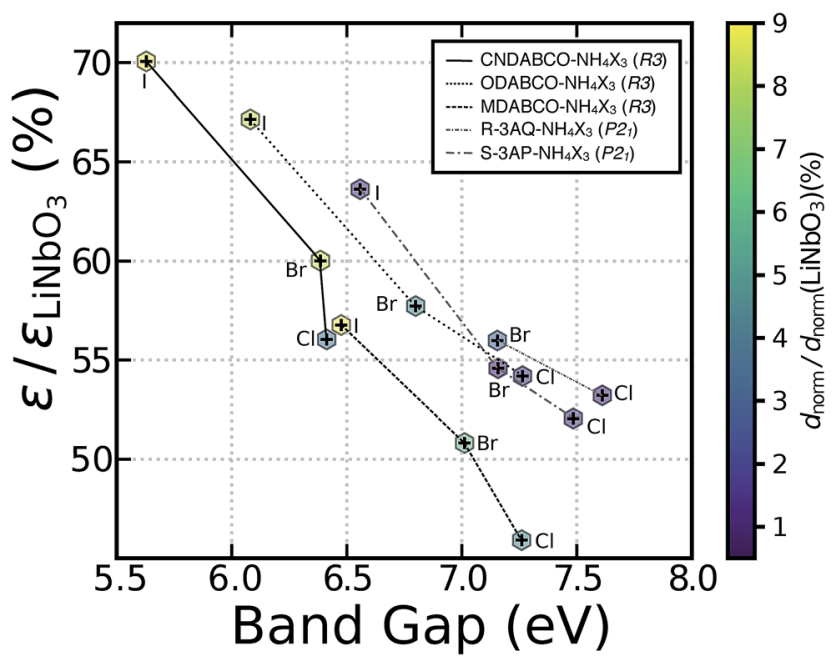

Fig. 3 Computed static $d_{\text {norm }}$ (colour-bar) as function of the band gap $(x$-axis, eV) and average dielectric constant ( $y$-axis) of the metal-free perovskites at the experimental volume. The $\varepsilon$ values (in the static limit) computed for the metal-free perovskites are normalized against the $\mathrm{LiNbO}_{3}$ ( 4.39). Similarly, the values of $d_{\text {norm }}$ are rescaled to that of $\mathrm{LiNbO}_{3}\left(\sim 17.91 \mathrm{pm} \mathrm{V}{ }^{-1}\right)$. The space group of each structure is also reported.

deep-UV portion of the electromagnetic spectrum, meaning that these materials fulfil another of the criteria for deep-UV SHG applications. All computed $d_{\text {norm }}$ values in metal-free perovskites with the same organic A-site cation follow the order I $>\mathrm{Br}$
$>$ Cl. The order of increasing $d_{\text {norm }}$ moving down the halide group follows the trend in band gaps. We find that the computed $d_{\text {norm }}$ of all the metal-free perovskites is a fraction (ranging between $1 \%$ and $10 \%$ ) of the $d_{\text {norm }}$ of $\mathrm{LiNbO}_{3}$ (Fig. 3), which is used as a reference.

From these data, we identify two iodine-based structures, MDABCO- $\mathrm{NH}_{4} \mathrm{I}_{3}$ and ODABCO- $\mathrm{NH}_{4} \mathrm{I}_{3}$ as the best NLO materials across the metal-free perovskites investigated. When the $\mathrm{OH}^{-}$ group in ODABCO- $\mathrm{NH}_{4} \mathrm{X}_{3}$ is replaced by a polar $\mathrm{CN}^{-}$group (see Fig. 3), forming CNDABCO- $\mathrm{NH}_{4} \mathrm{X}_{3}$, we find improved NLO properties. In CNDABCO- $\mathrm{NH}_{4} \mathrm{X}_{3}$, the computed $d_{\text {norm }}$ of $\sim 2.23$ pm $\mathrm{V}^{-1}$ outperforms all other metal-free perovskites, suggesting that CN-substituted A cations offer a promising strategy to improve the optoelectronic properties of these materials.

Fig. 3 shows that both $R-3 \mathrm{AQ}-\mathrm{NH}_{4} \mathrm{X}_{3}$ and $S-3 \mathrm{AP}-\mathrm{NH}_{4} \mathrm{X}_{3}$ posses small values of $d_{\text {norm }}$, covering a narrow range between $\sim 0.14$ and $\sim 0.52 \mathrm{pm} \mathrm{V}^{-1}$, with the highest value set by $R-3 \mathrm{AQ}-$ $\mathrm{NH}_{4} \mathrm{Br}_{3}$ and the lowest by $S-3 \mathrm{AP}-\mathrm{NH}_{4} \mathrm{Br}_{3}$. Hence, both $R-3 \mathrm{AQ}-$ $\mathrm{NH}_{4} \mathrm{X}_{3}$ and $S-3 \mathrm{AP}-\mathrm{NH}_{4} \mathrm{X}_{3}$ are expected to show low SHG behaviour and therefore, will not be considered further in this analysis.

\section{Discussion}

We have identified that $\mathrm{MDABCO}-\mathrm{NH}_{4} \mathrm{I}_{3}$, ODABCO- $\mathrm{NH}_{4} \mathrm{I}_{3}$ and CNDABCO- $\mathrm{NH}_{4} \mathrm{I}_{3}$ show the largest NLO response. Our results show the largest components of the $d$ tensor in MDABCO- $\mathrm{NH}_{4} \mathrm{I}_{3}$ are $d_{x x z}=d_{y y z} \sim 0.43 \mathrm{pm} \mathrm{V}^{-1}$ and $d_{x x y} \sim 1.20 \mathrm{pm} \mathrm{V}^{-1}$, respectively, $d_{y y y} \sim 0.84 \mathrm{pm} \mathrm{V}^{-1}$ in ODABCO- $\mathrm{NH}_{4} \mathrm{I}_{3}$ and $d_{y y y} \sim 1.31 \mathrm{pm}$ 
$\mathrm{V}^{-1}$ in CNDABCO-NH $\mathrm{H}_{4}$, which represent three promising NLO materials with good SHG. Therefore, the discussion will only focus on the subset of metal-free perovskites showing significant SHG activity, including CNDABCO- $\mathrm{NH}_{4} \mathrm{I}_{3}$, ODABCO$\mathrm{NH}_{4} \mathrm{X}_{3}$ and MDABCO-NH $\mathrm{N}_{4} \mathrm{X}_{3}$.

The values for SHG are similar and in most cases even larger than the prescribed minimal conditions for deep-UV applications, i.e. $d_{x y z} \sim 0.39 \mathrm{pm} \mathrm{V}^{-1}$ (with $\lambda \sim 1.064 \mu \mathrm{m}$ ) $\mathrm{KH}_{2} \mathrm{PO}_{4} \cdot{ }^{9{ }^{9} 37} \mathrm{The}$ calculated band gaps indicate that while the materials absorb in the $2 \omega$ range required for SHG, they do not absorb in the region $\omega$, a critical consideration, as absorption at $\omega$ would lead to material damage in operation. It is important to note that in a operation scenario the light absorbed will enhance the susceptibility but will also reduce the emission, thus the calculate values of $d_{x y z}$ serve to demonstrate the very promising properties of these materials for NLO and SHG applications, but should be considered as guides, rather than definitive numbers of real device operation. Most importantly, the compositionstructure-property relationships driving NLO response in these test systems can provide rules for designing even more SHG active materials.

As seen in Fig. 3, the primary factor influencing the size of $d_{\text {norm }}$ is the magnitude of the band gap. This is a well established trend in semiconductor materials in general and is related to lower carrier concentrations in wider gap materials at finite temperatures. A correlation between band gap and the halide species exists, we find a similar correlation in the values of the static dielectric constants $v s$. the anion species, following the trend $\varepsilon\left(\mathrm{I}^{-}\right)>\varepsilon\left(\mathrm{Br}^{-}\right)>\varepsilon\left(\mathrm{Cl}^{-}\right)$. This observation is consistent with the density of states of Fig. 4 of ODABCO- $\mathrm{NH}_{4} \mathrm{Br}_{3}$ (top), MDABCO- $\mathrm{NH}_{4} \mathrm{Br}_{3}$ (middle) and MDABCO- $\mathrm{NH}_{4} \mathrm{I}_{3}$ (bottom), respectively, which shows the valence band dominated by halide species and the conduction band populated by the A organic cation, i.e., $\mathrm{ODABCO}^{2+}$ or $\mathrm{MDABCO}^{2+}$. As the frontier valence orbitals are primarily halide in character (Fig. 4), it is not surprising that the largest change in band gap is controlled by halide exchange. These findings are also supported by the DOS presented in ref. 38 and are consistent with observations in hybrid halide perovskites. ${ }^{39}$

There is a secondary contribution to the $d_{\text {norm }}$ arising from the nature of the organic cation at the A-site. As seen in Fig. 3, $d_{\text {norm }}$ follows the order $d_{\text {norm }}\left(\mathrm{CNDABCO}^{2+}\right) \gg d_{\text {norm }}(-$ $\left.\mathrm{MDABCO}^{2+}\right)>d_{\text {norm }}\left(\mathrm{ODABCO}^{2+}\right)$. However, this trend becomes $d_{\text {norm }}\left(\mathrm{CNDABCO}^{2+}\right) \gg d_{\text {norm }}\left(\mathrm{ODABCO}^{2+}\right)>d_{\text {norm }}\left(\mathrm{MDABCO}^{2+}\right)$ when the structures are fully relaxed (see Table S5†). This is despite the fact that both $\mathrm{CNDABCO}^{2+}$ and $\mathrm{ODABCO}^{2+}$ systems have larger dielectric constants and smaller band gaps than the $\mathrm{MDABCO}^{2+}$ counterparts. As an example, while the ODABCO ${ }^{2+}$ cation is structurally very similar to the group $\mathrm{MDABCO}^{2+}$ (see Fig. 1), the apical methyl group in $\mathrm{MDABCO}^{2+}$ is substituted by a polar $\mathrm{OH}^{-}$in $\mathrm{ODABCO}^{2+}$. The presence of polar moieties in the organic cations, such as the $\mathrm{CN}^{-}$and $\mathrm{OH}^{-}$groups in $\mathrm{CNDABCO}^{2+}$ and $\mathrm{ODABCO}^{2+}$, can result in a greater intrinsic electric dipole moments, whose polarization induces an increase of the dielectric constant. The intrinsic electric dipole moment introduced by the $\mathrm{CN}^{-}$or the $\mathrm{OH}^{-}$groups increase the overall dipole of $\mathrm{CNDABCO}^{2+}$ from $\sim 3.61$ Debye to $~ 7.64$ Debye, compared to $\mathrm{MDABCO}^{2+} \sim 1.64$ Debye, which is reflected by the values of dielectric constants of Fig. 3.

Thus, the highly modular nature of the A site cation, in particular the DABCO group, afforded by a metal-free scaffold can be exploited to fine-tune the NLO response of these perovskites. For example, the substitution of the $\mathrm{CH}_{3}$ group on MDABCO with highly polar organic groups, such as -SH (thiol), $-\mathrm{NH}_{2}$ (amine), $-\mathrm{NO}$ (nitroso) and $-\mathrm{NO}_{2}$ (nitro), whose computed electric dipole moments are shown in Fig. $4 \mathrm{~b}$, represents a viable strategy to increase the NLO response of these metalfree perovskites. Indeed, in Fig. 2 we have demonstrated that

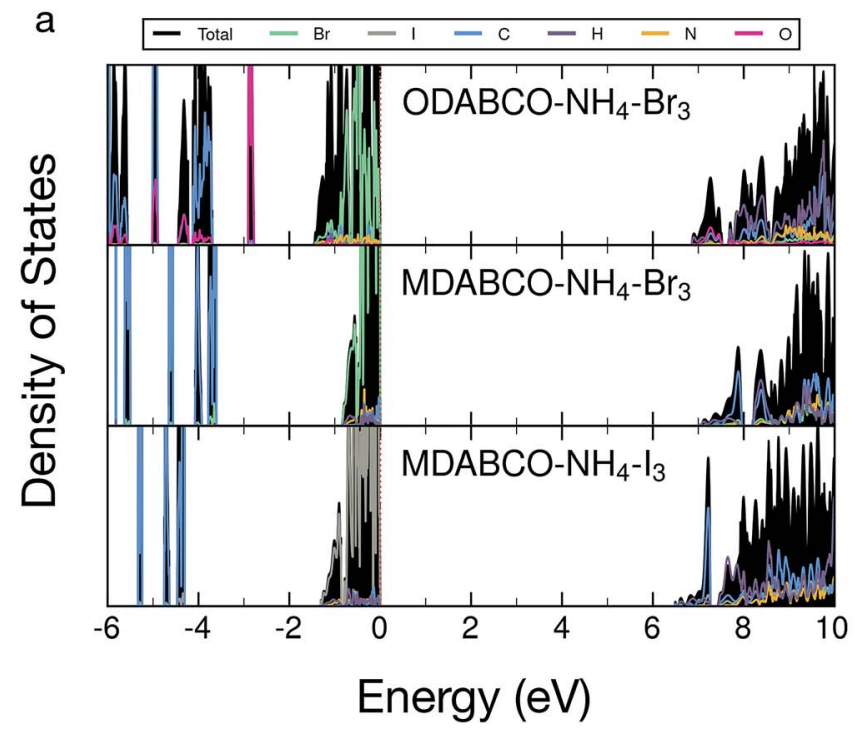

b
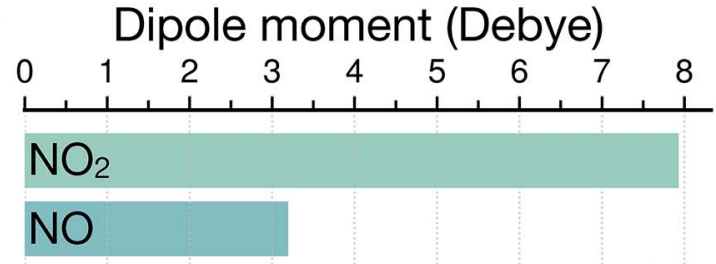

$\mathrm{CN}$

$\mathrm{NH}_{2}$

$\mathrm{SH}$

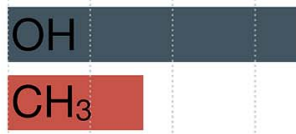

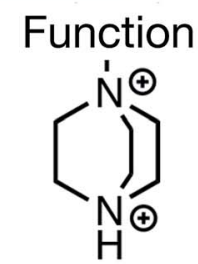

$\mathrm{DABCO}^{2+}$

Fig. 4 (a) Total and projected density of states of ODABCO-NH${ }_{4} \mathrm{Br}_{3}, \mathrm{MDABCO}-\mathrm{NH}_{4} \mathrm{Br}_{3}$ and MDABCO-NH $\mathrm{I}_{3}$ obtained with PBESol0-D3. The red line (dash) is the Fermi energy, which is set at the top of the valence band of each material. (b) Variance of dipole moment for DABCO cations substituted with a number of organic groups (functions). 
replacing the $\mathrm{CH}_{3}$ (or $\mathrm{OH}$ ) with the $\mathrm{CN}$ moiety, increases substantially the values of $d_{\text {norm }}$, thus providing a clear design rule to design novel metal-free perovskites.

The properties and tunability demonstrated in metal-free perovskites are comparable to organic-based NLO materials. Organic NLOs can supersede the performance in terms of descriptors, $\chi^{(2)}$ (see eqn (6)), even by 1-2 orders of magnitude of the inorganic NLO materials discussed so far., ${ }^{3,18-28}$ Some of these materials are even commercial., ${ }^{3,40,41}$ For example, the 4$N, N$-dimethylamino- $4^{\prime}-N^{\prime}$-methyl-stilbazolium tosylate (DAST) forms organic crystals with a superior non-linear susceptibility $d \sim 580 \mathrm{pm} \mathrm{V}^{-1}$ (with $d=0.5 \chi^{(2)}$ )..$^{21,25}$ However, organic-based NLOs display at least three major limitations curbing their use in optical devices: ${ }^{23,27}$ (i) difficult to obtain sufficiently largesize crystals, (ii) limited thermal stability above $200{ }^{\circ} \mathrm{C}$ and (iii) low mechanical strength. For example, while a good NLO organic material, such as the 3-methyl-4-methoxy-4'-nitrostilbene has a $1^{\text {st }}$ hyperpolarizability $\beta$ (see eqn (6)) approximately 300 times larger than the inorganic $\mathrm{KH}_{2} \mathrm{PO}_{4}$, it melts at $109{ }^{\circ} \mathrm{C}^{23}$ Metal-free perovskites also offer the potential to overcome these challenges.

All of the above trends are also dependent on crystal structure and therefore a further understanding of how composition and structure are related is required to achieve truly targeted synthesis. In systems like these metal-free perovskites an interplay of weak forces, such as dispersion, hydrogen bonding and entropy will be important for driving structure and phase transitions, as exemplified in the hybrid halide perovskites. ${ }^{\mathbf{4 2 , 4 3}}$

\section{Conclusions}

Using first-principles calculations, we have demonstrated the existence of NLO activity in a number of novel metal-free perovskites. In the past, density functional theory has been shown to systematically underestimate the values of $\chi_{i j k}^{(2)}$. While we believe the superior quality of hybrid DFT/PBESol0-based simulations may still underestimate $\chi^{(2)}$, our data show that MDABCO- $\mathrm{NH}_{4} \mathrm{I}_{3}$ and ODABCO- $\mathrm{NH}_{4} \mathrm{I}_{3}$ both fulfil the criteria to useful as deep-UV second-harmonic generation materials. We identify the role of the dipole moment imparted by the organic group on the A cation as an important parameter to tune the NLO properties of these materials. We apply this knowledge introducing the cyanide $\mathrm{CN}^{-}$group on the DABCO- $\mathrm{NH}_{4} \mathrm{X}_{3}$ structure, improving significantly the NLO properties of metalfree perovskites. Furthermore our systematic calculations allows us to extract useful trends to chart the second-harmonic generation properties of this novel class of materials. We have shown that the material band gap, and hence the $d_{\text {norm }}$ can be tuned by altering the halide anion. We also show the selection of the A-site cation provides an extra degree of tuning the $\chi^{(2)}$. By combining engineering of both the A- and X-sites we believe that these findings provide a blueprint for how to achieve high non-linear optics and second-harmonic generation activity in the desired part of the electromagnetic spectrum. We hope that these findings will help to accelerate the application of metalfree perovskites as non-toxic, earth-abundant materials for the next generation of optical communication applications.

\section{Linear and non-linear optic effects}

Materials respond differently to incident electromagnetic waves, whose induced electric polarization $P$ follows: ${ }^{33}$

$$
\begin{aligned}
P= & \varepsilon_{0}\left[\chi^{(1)} E+\chi^{(2)} E^{2}+\ldots+\chi^{(n)} E^{n}\right] \\
& =P^{(1)}+P^{(2)}+\ldots+P^{(n)}
\end{aligned}
$$

where $E$ is the electromagnetic field, $\varepsilon_{0}$ is the vacuum permittivity, and $\chi^{(1)}, \chi^{(2)}$ and $\chi^{(n)}$ are the $1^{\text {st }}, 2^{\text {nd }}$ and $n^{\text {th }}$ order electric susceptibilities. The dependence of the polarization on the $2^{\text {nd }}$ order term $\left(P^{(2)}\right)$ and successive electric susceptibilities suggests that the response of a permanent dipole in non-linear optical materials assumes an anharmonic behaviour once the electric dipole is perturbed by an incident electromagnetic radiation. ${ }^{33}$

Here, we assess the linear and NLO properties up to $\chi^{(2)}$ in the static regime, and accurately derived from first-principles calculations using the coupled perturbed Kohn-Sham theory (CPKS).$^{4,45}$ We compute the $n^{\text {th }}$-order derivatives of the total energy $E_{\text {Tot. }}$ with respect to derivatives of the electric field components in $\vec{\varepsilon}_{i j k}(i, j$ and $k$ are the Cartesian direction of the electric field), which are cast in the form of order- $n+1$ tensors. Such derivatives link to important optical descriptors, such as the electric dipole moment $\mu_{i}$ and the polarisability, $\alpha_{i j}$,

$$
\begin{gathered}
\mu_{i}=-\frac{\partial E_{\mathrm{Tot} .}}{\partial \vec{\varepsilon}_{i}} . \\
\alpha_{i j}=-\frac{\partial^{2} E_{\mathrm{Tot} .}}{\partial \vec{\varepsilon}_{i} \partial \vec{\varepsilon}_{j}} .
\end{gathered}
$$

From $\alpha_{i j}$, the components of the dielectric tensor $\varepsilon$ are derived as $\frac{\alpha_{i j}}{\varepsilon_{0} V}$ with $\varepsilon_{0}$ the vacuum permittivity and $V$ the unitcell volume. We note that $\varepsilon=n^{2}=1+\chi^{(1)}$, with $n$ the refractive index. $n$ and $\Delta n$ (of eqn (1)) are computed directly from the dielectric tensor.

The third-order rank tensor $\chi_{i j k}^{(2)}$ relates to $1^{\text {st }}$ hyperpolarizability $\beta_{i j k}$.

$$
\beta_{i j k}=-\frac{\partial^{3} E_{\text {Tot. }}}{\partial \vec{\varepsilon}_{i} \partial \vec{\varepsilon}_{j} \partial \vec{\varepsilon}_{k}}, \quad \text { with } \chi_{i j k}^{(2)}=\frac{2 \pi \beta_{i j k}}{V} .
$$

where $j$ and $k$ are the directions of the incident waves and $i$ the direction of the SHG wave. From eqn (3), $\chi_{i j k}^{(2)}$ links directly to the electric field that in materials is subjected to the spatially uniform electric fields of the incident radiations, and reads as:

$$
P_{i}^{(2)}\left(\omega_{1}+\omega_{2}\right)=\varepsilon_{0} \sum_{j, k} \chi_{i j k}^{(2)} \vec{\varepsilon}_{j}\left(\omega_{1}\right) \vec{\varepsilon}_{k}\left(\omega_{2}\right)
$$

where $\chi_{i j k}^{(2)}$ is a component of the $\chi^{(2)}$ tensor proportional to the polarization generated along the $i$-axis $(e . g ., x)$, from the $j$ and $k$ (e.g., $y$ and $z$ ) components of the electric fields of the incident radiations oscillating at frequencies $\omega_{1}$ and $\omega_{2}$, respectively. In SHG materials $\omega_{1}=\omega_{2}$.

Typically, $\chi_{i j k}^{(2)}$ is reported as $d_{i j k}=0.5 \chi_{i j k}^{(2)}$. Note that for hybrid functional calculations - the choice in this study-CRYSTAL17 computes only $\beta_{i j k}, \chi_{i j k}^{(2)}$ and $d_{i j k}$ values in the static limit. 


\section{First-principles calculations}

DFT is used to investigate the structural and optical properties of the metal-free perovskites. Structure relaxations of the experimental coordinates of the metal-free perovskites was performed using the PBESol $^{46}$ functional as in VASP. ${ }^{47-49}$ The Grimme D3 (ref. 50) correction was added to capture dispersive forces. The wave functions of the valence electrons were expanded with plane-waves with a cutoff of $520 \mathrm{eV}$, and core electrons were treated with the projector augmented wave theory. ${ }^{51}$ The Brillouin-zone was integrated on a mesh with reciprocal density of $64 k$-points per $\AA^{-1}$. The total energy was converged within $10^{-5} \mathrm{eV}$ and forces to $10^{-2} \mathrm{eV} \AA^{-1}$.

An accurate treatment of the electronic structure and in particular the assessment of the optical band gaps is crucial for the description of NLO properties. ${ }^{8,10,52}$ Starting from the PBEsol-D3 structures with VASP, we re-optimised the coordinates (or volume and coordinates) with the hybrid functional PBE0Sol-D3, ${ }^{46,53}$ including $25 \%$ of exact exchange as available in CRYSTAL17. ${ }^{54,55}$ We exploited the all-electron linear combination of atomic orbitals of CRYSTAL17 expanded by consistent triple- $\zeta$ plus polarization basis-sets, see ref. 56 and 57 . Given the electronic configuration of I $\left([\mathrm{Kr}] 4 \mathrm{~d}^{10} 5 \mathrm{~s}^{2} 5 \mathrm{p}^{5}\right)$ a fully-relativistic pseudo-potential is used..$^{58}$ The total energy was converged within $\sim 3 \times 10^{-9} \mathrm{eV}$ and integrated over a well converged and symmetrized $4 \times 4 \times 4 k$-point mesh (i.e., the shrinking factor is set to 4 ). The truncation of the (infinite) Coulomb and exchange series was set by the tolerances (TOLINTEG): $10^{-7}, 10^{-7}, 10^{-7}$, $10^{-7}$ and $10^{-30}$. Tables S1 and S2 of ESI $\uparrow$ show the PBE0Sol+D3 geometries. We computed the non-linear-optical properties with these settings. The iterative solution of the CPKS equations is reached for values below $10^{-4}$. Table S6 $\dagger$ shows a comparison of the performance of a number of DFT functionals.

The dipole moments of the DABCO units substituted by the organic groups were computed with Gaussian16 (ref. 59) using the PBE0+D3 (ref. 53) functional and the same basis-set used in the periodic calculations with CRYSTAL17.

\section{Author contribution}

P. C. and K. T. B. conceived the manuscript, performed the data analysis and wrote the first draft. T. W. K., A. M. M., C. H. H. and K. T. B. performed the initial VASP calculations. P. C., K. T. B. and Z. D. performed the CRYSTAL and Gaussian calculations. All authors contributed to the revision of the manuscript.

\section{Conflicts of interest}

There are no conflicts to declare.

\section{Acknowledgements}

P. C. acknowledges support from the Singapore Ministry of Education Academic Fund Tier 1 (R-284-000-186-133). The computational work for this article was partially performed on resources of the National Supercomputing Centre, Singapore (https://www.nscc.sg). This work benefited from access to the
University of Oregon high performance computer, Talapas. P. C. acknowledges Dr Y. Wu and Prof. A. K. Cheetham for useful discussion.

\section{Notes and references}

1 P. A. Franken, A. E. Hill, C. W. Peters and G. Weinreich, Phys. Rev. Lett., 1961, 7, 118-119.

2 G. D. Stucky, M. L. F. Phillips and T. E. Gier, Chem. Mater., 1989, 1, 492-509.

3 D. F. Eaton, Science, 1991, 253, 281-287.

4 J. L. Brédas, C. Adant, P. Tackx, A. Persoons and B. M. Pierce, Chem. Rev., 1994, 94, 243-278.

5 P. S. Halasyamani and K. R. Poeppelmeier, Chem. Mater., 1998, 10, 2753-2769.

6 T. Schneider, Nonlinear Optics in Telecommunications, Springer, Berlin, Heidelberg, 2004.

7 H. Wu, H. Yu, Z. Yang, X. Hou, X. Su, S. Pan, K. R. Poeppelmeier and J. M. Rondinelli, J. Am. Chem. Soc., 2013, 135, 4215-4218.

8 J. M. Rondinelli and E. Kioupakis, Annu. Rev. Mater. Res., 2015, 45, 491-518.

9 T. T. Tran, H. Yu, J. M. Rondinelli, K. R. Poeppelmeier and P. S. Halasyamani, Chem. Mater., 2016, 28, 5238-5258.

10 P. S. Halasyamani and J. M. Rondinelli, Nat. Commun., 2018, 9, 2972.

11 D. Cyranoski, Nature, 2009, 457, 953-955.

12 Niobium Price, https://www.metalary.com/niobium-price.

13 E. A. Olivetti, G. Ceder, G. G. Gaustad and X. Fu, Joule, 2017, 1, 229-243.

14 G. B. Olson, Science, 2000, 288, 993-998.

15 I. Chung and M. G. Kanatzidis, Chem. Mater., 2013, 26, 849869.

16 N. R. Goud, X. Zhang, J.-L. Brédas, V. Coropceanu and A. J. Matzger, Chem, 2018, 4, 150-161.

17 A. P. Wilkinson, A. K. Cheetham and R. H. Jarman, J. Appl. Phys., 1993, 74, 3080-3083.

18 J. Zyss, D. S. Chemla and J. F. Nicoud, J. Chem. Phys., 1981, 74, 4800-4811.

19 P. N. Prasad and D. J. Williams, Introduction to Nonlinear Optical Effects in Molecules and Polymers, John Wiley \& Sons, 1st edn, 1991.

20 T. Kaino and S. Tomaru, Adv. Mater., 1993, 5, 172-178.

21 F. Pan, G. Knöpfle, C. Bosshard, S. Follonier, R. Spreiter, M. S. Wong and P. Günter, Appl. Phys. Lett., 1996, 69, 13-15.

22 I. D. L. Albert, T. J. Marks and M. A. Ratner, J. Am. Chem. Soc., 1998, 120, 11174-11181.

23 M.-h. Jiang and Q. Fang, Adv. Mater., 1999, 11, 1147-1151.

24 W.-J. Kuo, G.-H. Hsiue and R.-J. Jeng, Macromolecules, 2001, 34, 2373-2384.

25 C. Bosshard, R. Spreiter, L. Degiorgi and P. Günter, Phys. Rev. B: Condens. Matter Mater. Phys., 2002, 66, 205107.

26 O. R. Evans and W. Lin, Acc. Chem. Res., 2002, 35, 511-522. 27 S. R. Marder, Chem. Commun., 2006, 131-134.

28 C. Wang, T. Zhang and W. Lin, Chem. Rev., 2011, 112, 10841104. 
29 H.-Y. Ye, Y.-Y. Tang, P.-F. Li, W.-Q. Liao, J.-X. Gao, X.-N. Hua, H. Cai, P.-P. Shi, Y.-M. You and R.-G. Xiong, Science, 2018, 361, 151-155.

30 H. Wu, S. Pan, K. R. Poeppelmeier, H. Li, D. Jia, Z. Chen, X. Fan, Y. Yang, J. M. Rondinelli and H. Luo, J. Am. Chem. Soc., 2011, 133, 7786-7790.

31 M. Veithen and P. Ghosez, Phys. Rev. B: Condens. Matter Mater. Phys., 2002, 65, 214302.

$32 \mathrm{~W}$. Zhang, H. Yu, H. Wu and P. S. Halasyamani, Chem. Mater., 2017, 29, 2655-2668.

33 R. W. Boyd, Nonlinear Optics, Academic Press as an imprint of Elsevier, 3rd edn, 2008.

34 J. Zyss and I. Ledoux, Chem. Rev., 1994, 94, 77-105.

35 G. A. Magel, M. M. Fejer and R. L. Byer, Appl. Phys. Lett., 1990, 56, 108-110.

36 Z. Lin, X. Jiang, L. Kang, P. Gong, S. Luo and M.-H. Lee, J. Phys. D: Appl. Phys., 2014, 47, 253001.

37 D. N. Nikogosyan, Properties of Optical and Laser-Related Materials, Wiley-Blackwell, 1997.

38 H. Wang, H. Liu, Z. Zhang, Z. Liu, Z. Lv, T. Li, W. Ju, H. Li, X. Cai and H. Han, npj Comput. Mater., 2019, 5, 17.

39 K. T. Butler, J. M. Frost and A. Walsh, Mater. Horiz., 2015, 2, 228-231.

40 T. Yamada, I. Aoki, H. Miki, C. Yamada and A. Otomo, Mater. Chem. Phys., 2013, 139, 699-705.

41 https:/www.tcichemicals.com/pdf/FF051E.pdf.

42 K. T. Butler, J. Mater. Chem. C, 2018, 6, 12045-12051.

43 G. Kieslich, J. M. Skelton, J. Armstrong, Y. Wu, F. Wei, K. L. Svane, A. Walsh and K. T. Butler, Chem. Mater., 2018, 30, 8782-8788.

44 M. Ferrero, M. Rérat, R. Orlando and R. Dovesi, J. Chem. Phys., 2008, 128, 014110.

45 M. Ferrero, M. Rérat, R. Orlando and R. Dovesi, J. Comput. Chem., 2008, 29, 1450-1459.

46 J. P. Perdew, A. Ruzsinszky, G. I. Csonka, O. A. Vydrov, G. E. Scuseria, L. A. Constantin, X. Zhou and K. Burke, Phys. Rev. Lett., 2008, 100, 136406.

47 G. Kresse and J. Hafner, Phys. Rev. B: Condens. Matter Mater. Phys., 1993, 47, 558-561.

48 G. Kresse and J. Furthmüller, Comput. Mater. Sci., 1996, 6, 15-50.

49 G. Kresse and J. Furthmüller, Phys. Rev. B: Condens. Matter Mater. Phys., 1996, 54, 11169-11186.
50 S. Grimme, J. Antony, S. Ehrlich and H. Krieg, J. Chem. Phys., 2010, 132, 154104.

51 G. Kresse and D. Joubert, Phys. Rev. B: Condens. Matter Mater. Phys., 1999, 59, 1758-1775.

52 V. Lacivita, M. Rérat, B. Kirtman, M. Ferrero, R. Orlando and R. Dovesi, J. Chem. Phys., 2009, 131, 204509.

53 C. Adamo and V. Barone, J. Chem. Phys., 1999, 110, 61586170.

54 R. Dovesi, V. R. Saunders, C. Roetti, R. Orlando, C. M. Zicovich-Wilson, F. Pascale, B. Civalleri, K. Doll, N. M. Harrison, I. J. Bush, P. D'Arco, M. Llunell, M. Causà, Y. Noël, L. Maschio, A. Erba, M. Rérat and S. Casassa, CRYSTAL17 User's Manual, University of Torino, Torino, 2017.

55 R. Dovesi, A. Erba, R. Orlando, C. M. Zicovich-Wilson, B. Civalleri, L. Maschio, M. Rérat, S. Casassa, J. Baima, S. Salustro and B. Kirtman, Wiley Interdiscip. Rev.: Comput. Mol. Sci., 2018, 8, e1360.

56 M. F. Peintinger, D. V. Oliveira and T. Bredow, J. Comput. Chem., 2012, 34, 451-459.

57 J. Laun, D. V. Oliveira and T. Bredow, J. Comput. Chem., 2018, 39, 1285-1290.

58 http://www.tc.uni-koeln.de/PP/clickpse.en.html.

59 M. J. Frisch, G. W. Trucks, H. B. Schlegel, G. E. Scuseria, M. A. Robb, J. R. Cheeseman, G. Scalmani, V. Barone, G. A. Petersson, H. Nakatsuji, X. Li, M. Caricato, A. V. Marenich, J. Bloino, B. G. Janesko, R. Gomperts, B. Mennucci, H. P. Hratchian, J. V. Ortiz, A. F. Izmaylov, J. L. Sonnenberg, D. Williams-Young, F. Ding, F. Lipparini, F. Egidi, J. Goings, B. Peng, A. Petrone, T. Henderson, D. Ranasinghe, V. G. Zakrzewski, J. Gao, N. Rega, G. Zheng, W. Liang, M. Hada, M. Ehara, K. Toyota, R. Fukuda, J. Hasegawa, M. Ishida, T. Nakajima, Y. Honda, O. Kitao, H. Nakai, T. Vreven, K. Throssell, J. A. Montgomery Jr, J. E. Peralta, F. Ogliaro, M. J. Bearpark, J. J. Heyd, E. N. Brothers, K. N. Kudin, V. N. Staroverov, T. A. Keith, R. Kobayashi, J. Normand, K. Raghavachari, A. P. Rendell, J. C. Burant, S. S. Iyengar, J. Tomasi, M. Cossi, J. M. Millam, M. Klene, C. Adamo, R. Cammi, J. W. Ochterski, R. L. Martin, K. Morokuma, O. Farkas, J. B. Foresman and D. J. Fox, Gaussian16 Revision B.01, Gaussian Inc., Wallingford CT, 2016. 